\title{
Use of the International Pharmaceutical Federation's Basel Statements to Assess and Advance Hospital Pharmacy Practice: A Scoping Review
}

\author{
Jonathan Penm, Betty Chaar, and Rebekah J Moles
}

\begin{abstract}
Background: The Basel statements of the International Pharmaceutical Federation, which provide the first global, unified vision for the hospital pharmacy profession, have recently been revised. Originally released in 2008, the Basel statements have since been made available in 21 languages, and thus have the potential for great impact around the world.
\end{abstract}

Objective: To conduct a scoping review to examine the extent and nature of research activity related to the Basel statements.

Methods: Google Scholar, PubMed, and International Pharmaceutical Abstracts were searched using the key term "Basel statements" for relevant research articles. From each included study, data were extracted on geographic location, study design, study outcomes, and use of the Basel statements.

Results: The search strategy generated 113 results. Further refinement resulted in 14 English-language articles that met the inclusion criteria. Four of these articles focused on adapting the Basel statements to European practice, an initiative of the European Association of Hospital Pharmacists that led to development of the European statements of Hospital Pharmacy. Six studies focused on monitoring hospital pharmacy practice in Uganda, the Pacific island countries, and the Western Pacific Region. These studies provide valuable baseline data to measure and track the development of hospital pharmacy practices in their respective countries and regions. The remaining 4 studies used qualitative methods to explore the barriers to and facilitators of implementation of the Basel statements in South Africa, China, and Australia.

Conclusion: The Basel statements have led to multiple initiatives around the world, involving more than 70 countries. The European and Western Pacific regions have been the most active. Current initiatives should be continued to ensure identification and resolution of issues related to sustaining their use over time.

Keywords: Basel statements, International Pharmaceutical Federation, hospital pharmacy practice, scoping review, global

Can J Hosp Pharm. 2016;69(2):131-7

\section{RÉSUMÉ}

Contexte : Les déclarations de Bâle de la Fédération internationale pharmaceutique, qui offrent la première vision mondiale unifiée pour la pharmacie hospitalière, ont été révisées récemment. D'abord rendues publiques en 2008, les déclarations de Bâle ont été traduites en 21 langues; elles peuvent ainsi avoir une grande portée partout dans le monde.

Objectif : Réaliser un examen de la portée et de la nature des recherches liées aux déclarations de Bâle.

Méthodes : Google Scholar, PubMed, et International Pharmaceutical Abstracts ont été interrogés à l'aide du mot clé « déclarations de Bâle " afin de trouver des articles de recherche pertinents. Pour chaque étude retenue, on a extrait des données sur le lieu, le plan de l'étude, les résultats de recherche et l'utilisation des déclarations de Bâle.

Résultats : La stratégie de recensement bibliographique a permis de trouver 113 articles. Une sélection plus affinée a permis de cerner 14 articles en anglais qui répondaient aux critères d'inclusion. Quatre articles portaient sur l'adaptation des déclarations de Bâle aux pratiques européennes; une initiative de l'European Association of Hospital Pharmacists qui a mené à l'élaboration des Déclarations européennes de la pharmacie hospitalière. Six portaient sur la surveillance des pratiques de la pharmacie hospitalière en Uganda, dans les États insulaires du Pacifique et dans la région du Pacifique occidental. Ces études fournissent d'importantes données de référence qui en retour permettent de mesurer et de suivre l'évolution des pratiques de la pharmacie hospitalière dans chacun des différents pays et régions. Dans les quatre derniers articles, des méthodes qualitatives ont été employées pour étudier les éléments qui font obstacle ou qui facilitent la mise en œuvre des déclarations de Bâle en Afrique du Sud, en Chine et en Australie.

Conclusion : Les déclarations de Bâle ont mené à de nombreuses initiatives partout dans le monde, auxquelles participent plus de 70 pays. La région de l'Europe et celle du Pacifique occidental ont été les plus actives. Les initiatives actuelles devraient être poursuivies afin d'identifier les enjeux liés au développement durable et de leur trouver des solutions.

Mots clés : déclarations de Bâle, Fédération internationale pharmaceutique, pratique de la pharmacie hospitalière, examen de la portée, mondial 


\section{INTRODUCTION}

T he International Pharmaceutical Federation (FIP) represents over 3 million pharmacists and pharmaceutical scientists around the world through 137 national organizations, as well as academic institutional and individual membership. ${ }^{1}$ In 2008, FIP representatives from 98 nations met in Basel, Switzerland, during the inaugural Global Conference on the Future of Hospital Pharmacy. ${ }^{2}$ One outcome of the conference was a set of consensus statements representing a global initiative to promote the practice of hospital pharmacy around the world. ${ }^{2}$ These statements, known as the Basel statements on the future of hospital pharmacy, are organized under several "overarching statements" and 6 themes: medicines procurement, influences on prescribing, preparation and delivery of medicines, administration of medicines, monitoring of medication practice, and human resources and training. ${ }^{2}$ The Basel statements are supported by evidence-based practices, with a strong focus on medication safety, as evidenced by literature reviews $s^{3-8}$ and a global survey of hospital pharmacy practices. ${ }^{9}$

Since their creation, the Basel statements have been made available in 21 languages, including the official languages of the United Nations. ${ }^{2}$ Furthermore, several international initiatives related to the Basel statements have emerged around the world. ${ }^{10,11}$ Recently, the FIP Hospital Pharmacy Section revised the Basel statements. ${ }^{12}$ The 65 revised Basel statements continue to provide a global, unified vision for the future of hospital pharmacy profession in an ever-changing health care environment. New additions to the Basel statements include hospital pharmacists' role in minimizing the environmental effects of pharmaceuticals and their expanding role related to information technology and informatics. ${ }^{12}$

In light of these initiatives and the release of the revised Basel statements, a scoping review was undertaken to examine the extent and nature of research activity related to the Basel statements.

\section{METHODS}

Google Scholar, PubMed, and International Pharmaceutical Abstracts were searched using the key term "Basel statements". Articles published in any language up to October 31, 2015, were eligible for inclusion. Original research studies that described any initiatives, changes, or impacts related to hospital pharmacy practice anywhere in the world due to the Basel statements were retained for analysis. Opinion pieces and commentaries were excluded.

The 3 authors independently screened the articles generated by the search strategy for relevance and inclusion on the basis of their titles and abstracts. Potential articles were then retrieved and reviewed by each author. Any discrepancies were discussed among the authors until consensus was achieved. Key components of the studies were extracted using a standardized form and then reviewed by all of the authors. The following data were extracted from each study: country or region where the study was conducted, study design, study outcomes, and use of the Basel statements.

\section{RESULTS}

The search strategy generated 113 results: 96 from Google Scholar, 12 from PubMed, and 5 from International Pharmaceutical Abstracts. Of these, 105 were in English; 2 each were in French, Spanish, and Italian; and 1 each were in German and Czech. After removal of duplicates and initial screening of titles, 27 full-text papers were retrieved and screened for further scrutiny. Further refinement resulted in 14 English articles that met the inclusion criteria (Figure 1).

Of the articles reviewed, 4 focused on adapting the Basel statements to the local environment, ${ }^{13-16} 6$ focused on monitoring hospital pharmacy practices using the Basel statements as comparative baseline standards, ${ }^{10,11,17-20}$ and 4 involved an indepth review of the factors affecting implementation of the Basel statements. ${ }^{21-24}$

\section{Local Adaptation of the Basel Statements}

Four articles focused on local adaption of the Basel statements, specifically in the European region. ${ }^{13-16}$ This task was an initiative of the European Association of Hospital Pharmacists (EAHP), a federation of national organizations in 34 countries representing hospital pharmacists across Europe. These articles grew out of a rigorous process by the EAHP to adapt the original Basel statements to the European region. The adapted statements are known as the European Statements of Hospital Pharmacy. ${ }^{25}$ The 4 identified articles were published together in an issue of the European Journal of Hospital Pharmacy.

The first article described the process used to identify which Basel statements were relevant to the European context. ${ }^{13} \mathrm{~A}$ working group of 15 hospital pharmacists, nominated by the EAHP from 13 countries, met and classified each Basel statement according to its impact on patients and its relevance to hospital pharmacy practice in Europe. The working group thought that many of the Basel statements could be merged, which resulted in a total of $48 \mathrm{draft}$ European statements based on the original 75 Basel statements.

The second article described efforts to ensure that the draft European statements achieved a high level of consensus in Europe. ${ }^{14}$ These efforts included both a Delphi process and a "World Café" process involving EAHP members and representatives from patient and other health care professional groups to achieve consensus. The draft European statements were first subjected to 2 online rounds of the Delphi process, but the outcomes were only minor word changes and some additional statement mergers. Next, the statements underwent further consensus-building with the World Café process. This face-to- 


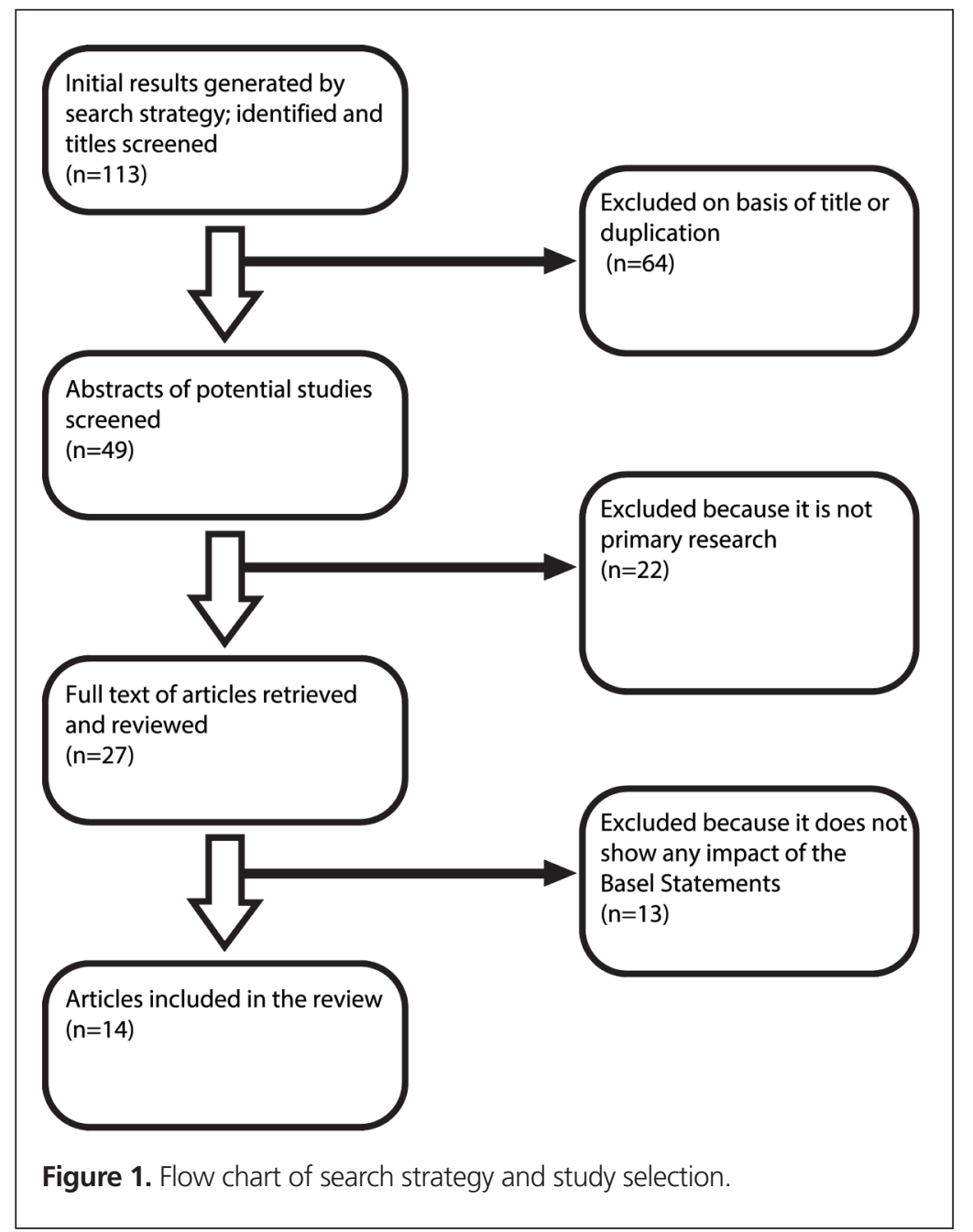

face meeting involved 31 national hospital pharmacy associations and 21 organizations representing patients and other health care professionals. Again, minor word changes were made to simplify some statements and improve the flow within groups of statements. In particular, an effort was made to ensure that the word "must" was used only if the statement was a minimum requirement; the word "should" was used if there was recognition that adopting the statement might be aspirational for some countries. At the end of the Delphi and World Café processes, a set of 44 revised European statements had been developed. ${ }^{14}$ These statements were then voted upon for final agreement. In this voting process, $50 \%$ of the overall votes were awarded to hospital pharmacist associations, $25 \%$ to health care professional organizations, and $25 \%$ to patient organizations. ${ }^{26}$ The vote resulted in agreement on all 44 European statements, the first local adaptation of the Basel statements anywhere in the world.

The remaining 2 articles in this category were qualitative studies of the perspectives of EAHP members ${ }^{15}$ and patients and other health care professionals ${ }^{16}$ on the benefits of adapting the Basel statements to Europe. The EAHP members felt that the
European statements would encourage their members to strive for improved services and to discuss the statements with their respective governments and other key stakeholders. ${ }^{15}$ Patients and other health care professionals stated their belief that the European statements would allow them to have a deeper appreciation and knowledge of hospital pharmacy. ${ }^{16}$ Patient groups were noted to have engaged in the process with great enthusiasm, while other health care professionals initially participated with caution. ${ }^{16}$ As a whole, engagement with stakeholders outside of hospital pharmacy was considered beneficial and would have been even more advantageous had it occurred earlier in the process. ${ }^{16}$

\section{Monitoring of Hospital Pharmacy Practices with the Basel Statements}

Six studies focused on monitoring hospital pharmacy practices in different countries using the Basel statements as comparative baseline standards..$^{10,11,17-20}$ These studies were conducted in Uganda, ${ }^{20}$ the Pacific island countries, ${ }^{19}$ and the Western Pacific Region, which encompasses 37 countries. ${ }^{10,11,17,18}$ 
In 2 of these studies, Penm and others ${ }^{17,18}$ reported validation of monitoring surveys for face, content, and construct validity. However, undertaking such a rigorous process necessitated limiting these analyses to the theme of "influences on prescribing" (which encompasses Basel statements 26 to 31). The first validated survey, known as the BS26-27 survey, focused on Basel statements 26 and 27, which relate to formulary systems and pharmacy and therapeutics committees. ${ }^{10}$ The second validated survey, known as the BS28-31 survey, focused on Basel statements 28 to 31 , which relate to clinical pharmacy services that influence prescribing. ${ }^{11}$ The 2 surveys were used to monitor hospital pharmacists' influences on prescribing in the Western Pacific region. To encourage responses from all nations in this region, the surveys were translated into 8 languages. The BS26-27 survey attained a response rate of 40\% (797 responses from 1989 hospital pharmacy directors in 34 nations), whereas the BS28-31 survey attained a response rate of 29\% (726 responses from 2525 hospital pharmacy directors in 31 nations).

The BS26-27 survey reported that 87\% (691 of 797) of responding hospitals in the Western Pacific Region used a formulary, and $93 \%$ (619 of 664) of respondents indicated that their hospital had a pharmacy and therapeutics committee. ${ }^{10}$ However, only $44 \%$ (274 of 626 ) of respondents reported that the majority of their formulary medicines were linked to standard treatment guidelines. ${ }^{10}$ Furthermore, 91\% (658 of 726) of respondents stated that their hospitals provided clinical pharmacy services and education to prescribers, but an average of only $28 \%$ of clinical pharmacists were reported to regularly attend medical rounds (based on data from 527 hospitals providing relevant data).

From these studies, it was noted that pharmacy directors perceived the benefits of formularies as being correlated with having more formulary medicines linked to standard treatment guidelines, basing the formularies on the best available evidence, and having a policy for the off-label use of medicines. ${ }^{10}$ Additionally, higher scores for internal facilitators, such as the traits of individual pharmacists and the structure and resources of the pharmacy department, were significantly associated with increased likelihood of offering clinical services and having pharmacists regularly attend medical rounds. ${ }^{11}$ Moreover, higher scores for environmental facilitators, including government support and the expectations of patients and physicians, and having a higher percentage of pharmacists regularly attend medical rounds significantly increased the likelihood of inpatients receiving a medication history, a medication review, and discharge counselling by a pharmacist. ${ }^{11}$

A subgroup analysis of the Pacific island countries, using data from the BS26-27 and BS28-31 surveys, was also conducted. The Pacific island countries are 22 independent nations comprising more than 7500 islands in the Western Pacific Region. ${ }^{27}$ The subgroup analysis included the 55 hospitals ( $77 \%$ of 71 hospitals contacted) that responded to either of the 2 surveys. ${ }^{19}$ From the responses received, 97\% (36 of 37 ) of the hospitals reported having a formulary, and $81 \%$ (26 of 32) reported having a pharmacy and therapeutics committee. ${ }^{19}$ Furthermore, $67 \%$ of respondents (24 of 36) stated that they provided some sort of clinical pharmacy service, and on average, these hospitals had 2 pharmacists involved in clinical pharmacy services. ${ }^{19}$ More than $75 \%$ of respondents to the BS28-31 survey believed that having a strong relationship with other health care professionals, having effective communication skills, and taking professional responsibility for the medicines prescribed were strong facilitators for clinical services. ${ }^{19}$

These studies ${ }^{10,11,17-19}$ provide a snapshot of hospital pharmacy practices in the Western Pacific Region in relation to the Basel statements at a point in time close to their initial dissemination, and the development of these validated tools will allow for ongoing monitoring.

Elsewhere, Poh and others ${ }^{20}$ used the Basel statements to monitor hospital pharmacy practices at a single site, St Mary's Lacor Hospital in the Gulu district of Uganda. In that study, the Basel statements were shown to offer a global perspective on assessing a medication management system in a country that had not adopted a national drug management standard. The study hospital was assessed, in 2009, 2011, and 2012, as having "met", "partially met", or "not met" each Basel statement; statements that were "not applicable" were also identified. The total number of Basel statements met rose from 18 in 2009 to 35 in 2012. ${ }^{20}$ Additionally, the number of Basel statements designated as "not applicable" decreased from 18 to 14 over this period. As a result, these serial assessments provided a framework for an overall improvement process in the hospital.

\section{Factors Affecting Implementation of the Basel Statements}

Four studies, conducted in South Africa, ${ }^{21,24} \mathrm{China}^{23}$ and Australia, ${ }^{22}$ used qualitative methods to explore the barriers to and facilitators of implementing the Basel statements.

The South African Association of Hospital and Institutional Pharmacists conferences in $2010^{21}$ and $2011^{24}$ both invited key pharmacy opinion leaders to discuss issues surrounding implementation of the Basel statements in South Africa. At both conferences, it was highlighted that human resources were a particular problem in the public health sector. ${ }^{21,24}$ Representatives of the private sector also stated that it was difficult to implement formularies, because physicians valued their freedom of choice. ${ }^{21}$

An in-depth study in China, involving interviews with hospital administrators, pharmacy directors, clinical pharmacists, and dispensing pharmacists, was conducted to identify the factors affecting clinical pharmacy services. ${ }^{23}$ The interview guide was based on the Basel statements theme "influences on prescribing". The study was based on 30 group and individual interviews with 
a total of 130 participants at 29 hospitals (both secondary and tertiary care) in Beijing, Zhengzhou, Luoyang, and Shanghai. ${ }^{23}$ Themes from the interviews were then mapped to an adapted version of an existing organizational model to develop a holistic view of the pharmacy department within a hospital. In this model, the components of an organization are described as participants, social structure, goals, technology, and environment. Further details on how these components are defined in pharmacy have been presented previously. ${ }^{28,29}$ In the Chinese study, the themes identified corresponded to the environment and participant dimensions of the organizational model. ${ }^{23}$ Environmental support from government and hospital administrators was perceived as crucial to promoting pharmacy services, particularly in a country where incentives to overprescribe may exist. ${ }^{23}$

In another study, qualitative interviews conducted in Australia were based on Basel statement 32, regarding initiation of postgraduate prescribing courses for hospital pharmacists. ${ }^{22}$ In that study, 25 interviews were conducted with academics, hospital pharmacists, and professional organizations. The consensus from the interviews was a proposal that postgraduate training for hospital pharmacists should be based on a national prescribing competency framework. ${ }^{22}$ In addition, participants highlighted key aspects of the prescribing process, whereby pharmacists need specific skill development in the following domains: diagnosis, physical assessments, clinical decisionmaking, and consultations. ${ }^{22}$ The training model used in the United Kingdom was favoured, with candidates undertaking university-based study combined with collaborative training with a doctor and a practical assessment of competency.

These studies ${ }^{21-24}$ highlighted multiple barriers to implementation of the Basel statements and identified the need to identify ways of achieving implementation.

\section{DISCUSSION}

Since creation of the Basel statements in 2008, they have been translated into 21 languages, to aid their dissemination and use around the world. ${ }^{3}$ Although the FIP has not initiated any additional interventions to disseminate the Basel statements, various researchers and hospital pharmacy associations in more than 70 countries have been applying and using them. The European and Western Pacific regions have been the most active, with 34 countries in each region participating in research related to the Basel statements. These initiatives, and the international nature of the statements, have also led to the founding of a global network of hospital pharmacy researchers known as the World Hospital Pharmacy Research Consortium (WHoPReC). ${ }^{30}$ WHoPReC aims to produce high-quality, internationally focused research on hospital pharmacy practices to improve health outcomes, currently basing its work on the Basel statements because of their worldwide applicability. ${ }^{30}$
Since initial development of the Basel statements, research has focused on methods of facilitating their implementation. These methods mirror those presented in the knowledge-toaction cycle commonly used in implementation research (Figure 2). ${ }^{31}$ The knowledge-to-action cycle represents a framework for the implementation of knowledge and has been used for the implementation of guidelines in various health care settings worldwide. ${ }^{32}$

The creation of the Basel statements represents the knowledge creation funnel depicted in the knowledge-to-action cycle. Following creation of this new information, researchers have focused on the 7 aspects of the action cycle: identifying the problem; adapting the knowledge to the local context; assessing barriers to knowledge use; selecting, tailoring, and implementing the intervention; monitoring knowledge use; evaluating outcomes; and sustaining knowledge use.

The current analysis identified different problems addressed by each of the included studies and grouped them into 3 overarching issues. The EAHP identified which Basel statements were relevant to the European region and adapted them to the local setting. ${ }^{13-16}$ The researchers in Uganda, the Pacific island countries, and the Western Pacific Region determined the extent to which the Basel statements had been implemented in their respective hospitals or regions. ${ }^{10,11,17-20}$ The researchers in China, South Africa, and Australia identified barriers to and strategies for implementing the Basel statements. ${ }^{21-24}$

Numerous interventions have been used to address each of these areas, including the Delphi method, the World Café process, survey development and data collection, and in-depth qualitative interviews. However, only the research in Uganda ${ }^{20}$ considered the topic of sustained knowledge use (phase 7 of the knowledge-to-action cycle), by conducting a longitudinal study that surveyed the target population 3 times over a period of 4 years. In that study, the survey itself was the only intervention used to promote sustained application of the Basel statements. ${ }^{20}$ Similar to global implementation research, longitudinal studies investigating how to sustain the use of knowledge are scarce. ${ }^{31}$ However, this type of research is crucial, as the barriers present when the knowledge is first introduced may be different from the barriers present as time goes on. As such, repeated evaluations of the problems described above are strongly encouraged to ensure sustained use of knowledge. In particular, surveys that have already been used to monitor implementation of the Basel statements should be used on a regular basis in the future to highlight issues related to their sustainability.

Although most of the research identified in this scoping review was performed primarily in hospital pharmacy departments, some researchers have taken a more holistic view by including the hospital environment surrounding the pharmacy department in their study designs. This was highlighted in the study from China, which used organizational theory in researching clinical pharmacy services. ${ }^{23}$ In that 


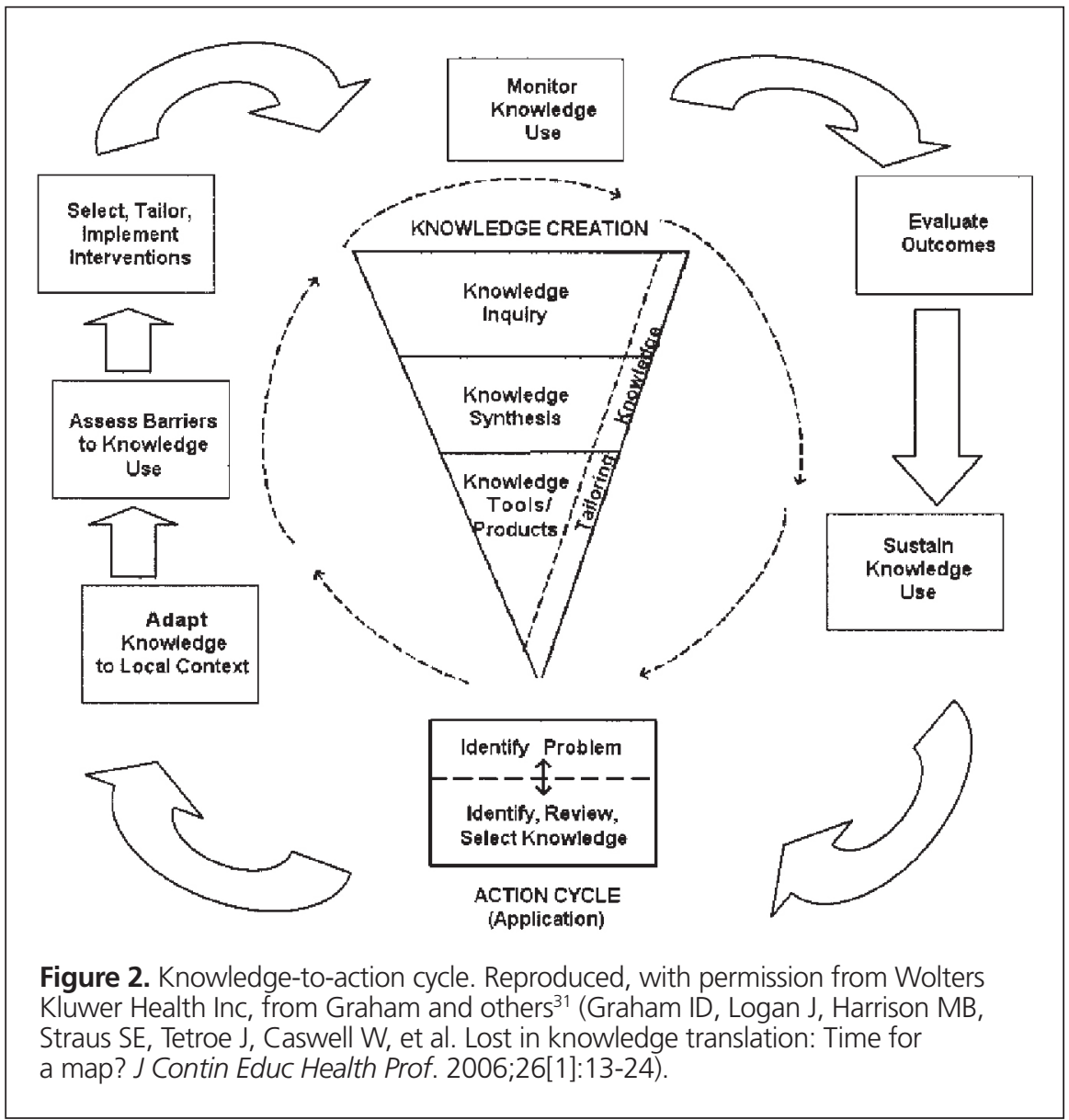

research, the pharmacy department was seen as a distinct organization operating within a hospital. As such, the relationship of the pharmacy department to patients and other departments within the hospital was perceived as having profound effects on the pharmacy department itself. ${ }^{23}$ The EAHP pursued this concept by including both patients and other health care professionals in their adaptation of the Basel statements in the European region. ${ }^{16}$ Both studies found it beneficial to include those outside the pharmacy profession, with patients often advocating for additional pharmacy services more than the pharmacists themselves. ${ }^{16,23}$ It therefore follows that further research focused on gaining support from patients and other health care professionals would be beneficial, even though this element is often missing from current hospital pharmacy research.

Although the Basel statements provide a futuristic vision of where the hospital pharmacy profession should be going, they do not give direction on how the statements should be implemented. ${ }^{13,24,33}$ With multiple gaps in hospital pharmacy practice identified in different countries and regions, practitioners are often unsure which particular statements should have priority. Although literature reviews were conducted to support each of the initial Basel statements when they were first developed, neither the quality of the evidence nor the impact of the evidence on patients was evaluated. Furthermore, of the 14 studies reviewed, only the one from Uganda provided comparative measures against baseline data to highlight the impact that the Basel statements can have on practice; no studies have examined the impact of the statements on patient care. It is therefore recommended that the following research be conducted to aid implementation of the Basel statements: identify which Basel statements should be considered global minimum standards for hospital pharmacy practices $^{33}$; identify the impact on patient care that each Basel statement could have, listing the grade of evidence for each statement; and compile suggested steps on how to implement the Basel statements.

Some limitations to this analysis can be noted. The Basel statements represent only one of many initiatives on the global scene for advancing hospital pharmacy practice. Many developed countries have highly functional professional associations of hospital pharmacists, and several of those associations have for many years had effective programs for improving hospital pharmacy practice unrelated to the Basel statements. Also, this review may have publication bias, as some research activities related to the Basel statements may remain unpublished, and only the English term "Basel statements" was used to search the literature. An additional limitation of this review is that some 
studies included in the analyses were conducted by the authors themselves. Although this may bias the interpretation of these studies, we also acknowledge that all of the included studies underwent rigorous external review through the peer review systems of the respective journals in which they were published.

\section{CONCLUSION}

The Basel statements have provided a platform for international hospital pharmacy research. The most notable initiatives have occurred in the European and Western Pacific regions. The founding of WHoPReC was inspired by the Basel statements, and this organization will further promote hospital pharmacy research globally. Current initiatives should be continued to ensure identification and resolution of issues related to sustaining use of these statements over time. Additionally, current initiatives have highlighted the importance of including patients and other health care professionals in research relating to hospital pharmacy, and such initiatives should be further encouraged. Additional research should aim to aid practitioners in prioritizing the Basel statements for future implementation around the world.

\section{References}

1. Who we are and what we do [webpage]. The Hague (Netherlands): International Pharmaceutical Federation; [cited 2015 Oct 26]. Available from: www.fip.org/basel-statements?page=menu_about

2. International Pharmaceutical Federation. The Basel statements on the future of hospital pharmacy. Am J Health Syst Pharm. 2009;66(5 Suppl 3):S61-6.

3. Cousins D. Current status of the monitoring of medication practice. Am J Health Syst Pharm. 2009;66(5 Suppl 3):S49-56.

4. Nissen L. Current status of pharmacist influences on prescribing of medicines. Am J Health Syst Pharm. 2009;66(5 Suppl 3):S29-34.

5. Oishi R. Current status of preparation and distribution of medicines. Am J Health Syst Pharm. 2009;66(5 Suppl 3):S35-42.

6. Ombaka E. Current status of medicines procurement. Am J Health Syst Pharm. 2009;66(5 Suppl 3):S20-8.

7. Shane R. Current status of administration of medicines. Am J Health Syst Pharm. 2009;66(5 Suppl 3):S42-8.

8. Wuliji T. Current status of human resources and training in hospital pharmacy. Am J Health Syst Pharm. 2009;66(5 Suppl 3):S56-60.

9. Doloresco F, Vermeulen LC. Global survey of hospital pharmacy practice. Am J Health Syst Pharm. 2009;66(5 Suppl 3):S13-9.

10. Penm J, Chaar B, Dechun J, Moles R. Formulary systems and pharmacy and therapeutics committees in the Western Pacific Region: exploring two Basel statements. Am J Health Syst Pharm. 2013;70(11):967-79.

11. Penm J, Chaar B, Moles R. Clinical pharmacy services that influence prescribing in the Western Pacific Region based on the FIP Basel statements. Int J Clin Pharm. 2015;37(3):485-96.

12. International Pharmaceutical Federation, Hospital Pharmacy Section. Revised FIP Basel statements on the future of hospital pharmacy. The Hague (Netherlands): International Pharmaceutical Federation; [cited 2015 Oct 26]. Available from: www.fip.org/files/fip/FIP_BASEL_STATEMENTS_ ON_THE_FUTURE_OF_HOSPITAL_PHARMACY_2015.pdf

13. Batista A, Preece D. Forming the initial European Statements of Hospital Pharmacy. Eur J Hosp Pharm. 2014;21(5):259-61.

14. Maskrey N, Underhill J. The European Statements of Hospital Pharmacy: achieving consensus using Delphi and World Café methodologies. Eur J Hosp Pharm. 2014;21(5):264-6.

15. Preece D. The European Statements of Hospital Pharmacy: the perspective of EAHP members. Eur J Hosp Pharm. 2014;21(5):279-81.

16. Price R. The European Statements of Hospital Pharmacy: the patient and healthcare perspective. Eur J Hosp Pharm. 2014;21(5):276-8.
17. Penm J, Chaar B, Rose G, Moles R. Pharmacists' influences on prescribing: validating a clinical pharmacy services survey in the Western Pacific Region. Res Social Adm Pharm. 2015;11(1):63-73.

18. Penm J, Chaar B, Moles R. Validating a hospital medicines formulary survey in the Western Pacific Region - a global hospital pharmacy initiative based on the Basel statements. Res Social Adm Pharm. 2012;8(4):298-308.

19. Penm J, Chaar B, Moles R. Hospital pharmacy services in the Pacific Island countries. J Eval Clin Pract. 2015;21(1):51-6.

20. Poh J, Vaillancourt R, Lamarre D, Oyella J. Use of the 2008 Basel consensus statements to assess, realign, and monitor pharmacy practice at a tertiary care hospital in northern Uganda: illustrative case study. Can J Hosp Pharm. 2013;66(5):318-27.

21. Gray A. Global standards, South African practice-report of a workshop. S Afr Pharm J. 2010;77(5):45-8.

22. Kamarudin G, Penm J, Chaar B, Moles R. Preparing hospital pharmacists to prescribe: stakeholders' views of postgraduate courses. Int J Pharm Pract. 2013;21(4):243-51.

23. Penm J, Moles R, Wang H, Li Y, Chaar B. Factors affecting the implementation of clinical pharmacy services in China. Qual Health Res. 2014;24(3): 345-56.

24. Pillaye T. Safe systems in hospitals: applying the Basel statements. S Afr Pharm J. 2011;78(7):38-9.

25. The European Statements of Hospital Pharmacy [editorial]. Eur J Hosp Pharm. 2014;21(5):256-8.

26. Frontini R. The voting system. Eur J Hosp Pharm. 2014;21(5):267-9.

27. Gal D, editor. 2012 FIP Global Pharmacy Workforce report. The Hague (The Netherlands): International Pharmaceutical Federation; 2012.

28. Hopp TR, Sørensen EW, Herborg H, Roberts AS. Implementation of cognitive pharmaceutical services (CPS) in professionally active pharamcies. Int J Pharm Pract. 2005;13(1):21-31.

29. Roberts AS, Hopp T, Sørensen EW, Benrimoj SI, Chen TF, Herborg H, et al. Understanding practice change in community pharmacy: a qualitative research instrument based on organisational theory. Pharm World Sci. 2003; 25(5):227-34.

30. Moles R, Chaar B, Penm J. The World Hospital Pharmacy Research Consortium - monitoring global practice in relation to the Basel Statements [editorial]. Can J Hosp Pharm. 2014;67(5):331-2.

31. Graham ID, Logan J, Harrison MB, Straus SE, Tetroe J, Caswell W, et al. Lost in knowledge translation: Time for a map? J Contin Educ Health Prof. 2006;26(1):13-24.

32. Harrison MB, Légaré F, Graham ID, Fervers B. Adapting clinical practice guidelines to local context and assessing barriers to their use. CMAJ. 2010;182(2):E78-84.

33. Thompson CA. International hospital pharmacy section's work on Basel statements continues. Am J Health Syst Pharm. 2012;69(23):2030-2.

Jonathan Penm, BPharm(Hons), PhD, is a postdoctoral fellow at the James L Winkle College of Pharmacy, University of Cincinnati, Cincinnati, Ohio.

Betty Chaar, BPharm, MHLaw, PhD, is a Senior Lecturer with the Faculty of Pharmacy, University of Sydney, Sydney, New South Wales, Australia.

Rebekah J Moles, BPharm, DipHospPharm, PhD, GradCertEdStud(Higher Ed), is a Senior Lecturer with the Faculty of Pharmacy, University of Sydney, Sydney, New South Wales, Australia. She is also an Associate Editor with the CJHP.

\section{Competing interests: None declared}

\section{Address correspondence to:}

Dr Jonathan Penm

James L Winkle College of Pharmacy

University of Cincinnati

3225 Eden Avenue

Cincinnati OH 45267 USA

e-mail: jonathan.penm@uc.edu

Funding: None received. 